\title{
GEOMATIC TECHNIQUES FOR MONITORING AND VERIFYING OF THE WEAR CONDITION OF THE RUNWAYS OF THE BRIDGE CRANES
}

\author{
D. Costantino ${ }^{\mathrm{a}}$, M.Pepe ${ }^{\mathrm{a}}$, V. Alfio $^{\mathrm{a}}$, M. Carrieri ${ }^{\mathrm{b}}$ \\ a DICATECh, Polytechnic of Bari, 70126 Bari, Italy - domenica.costantino@poliba.it \\ b AESEI s.r.l. Spin Off - Polytechnic of Bari, 74015 Martina Franca (TA), Italy
}

Commission II

KEY WORDS: Integrated survey, TLS, Photogrammetry, Monitoring, Runways

\begin{abstract}
:
Monitoring and diagnostics of the lifting systems in the field of rail transport play a fundamental role in order to enable it to function safely providing any deviations from the expected behaviour of the regular conditions. The transit of heavy convoys naturally tends to worsen the geometrical position and, of consequence, it is necessary to identify some monitoring techniques that allow to establish the maintenance of infrastructure in accordance with the standards UNI ISO 9927-1 and in according to ISO 12488-1 must be verify the tolerance for wheels and travel and traversing tracks; for a crane runway these are for example the span, the position and height of the rails.. Especially the ground infrastructure related to the bridge crane requires periodic checks. The purpose of this paper is to identify suitable geomatics techniques for monitoring of the runways of the bridge cranes. To achieve this aim, the paper is divided in more sections. In the first part, the paper describes the area involved in the monitoring and standards in the field of monitoring the wear of the rails. In the second part, the paper describes the criteria and regulations for checking the wear of the bridge cranes using several geomatics techniques, tool and software.
\end{abstract}

\section{INTRODUCTION}

Modern Monitoring and diagnostics of the lifting systems play a fundamental role in order to enable it to function safely providing any deviations from the expected behaviour of the regular conditions. The transit of heavy convoys naturally tends to worsen the geometrical position is, therefore, necessary that such techniques are regularly carried out in order to establish the maintenance or rebuilding of infrastructure in accordance with the standards UNI ISO 9927-1 and UNI ISO 12488-1. In particular, the ground infrastructure related to the bridge crane requires periodic checks especially the type rail mounted transtainer.

The rail profiles may have different defects. It is possible to distinguish between visually recognizable (rail wear, discontinuities at the rail joints etc) and non-recognizable (span distance, straightness etc) defects.

The monitoring can be done with classic topographic techniques by the use of total station and level instrument in order to survey the position of crane rail in ground plan and the height of crane rail (axial slope) and the height of travelling track (lateral slope). This approach was applied by Marjetič et al., 2012 that have developed a simple tool to improve the accuracy of the height determination with total stations.

Over the years, highly automated solutions have been developed that allow dimensional checks to be carried out. These solutions make use of different sensors, such as laser scanners, odometers, inertial and global positioning systems. (Neumann, et al 2012, Dennig, et al 2017). However, these systems are rather expensive and not always usable during the crane operation phase.

There are different issues regarding the state of track wear, for which it is possible to adopt new surveying techniques, such as Image Based 3D Modelling (IBM) or Range-based Modelling.

IBM methods use 2D image measurements to obtain 3D model information. The range-based modelling is based on active sensors which provide highly detailed end accurate representation of 3D object; in general, this sensor is still expensive (Remondino et al., 2006).

In the paper is describe the survey carried out by terrestrial laser scanner (TLS), photogrammetry (terrestrial and aerial) and traditional survey (Total Station, level).

\section{TARANTO CONTAINER TERMINAL (TCT)}

The port of Taranto has a strategic geographical position in the Mediterranean centre of gravity compared to the main routes between East and West and is an ideal centre for maritime traffic between Europe and the rest of the world, as well as for short-haul domestic and European traffic. The slipway, located on the northern coast of the homonymous Gulf, is a natural harbour formed by a large bay known as the Great Sea and inner cove called Little Sea. Port installations are distributed along the north-western area of the Great Sea, immediately off of it to the West.

The port of Taranto (Figure 1) is characterized by multifunctionality, from the division of moorings in relation to different productive sectors: commercial, industrial, petroleum and tourism (with the landing sites in the east of the airport).
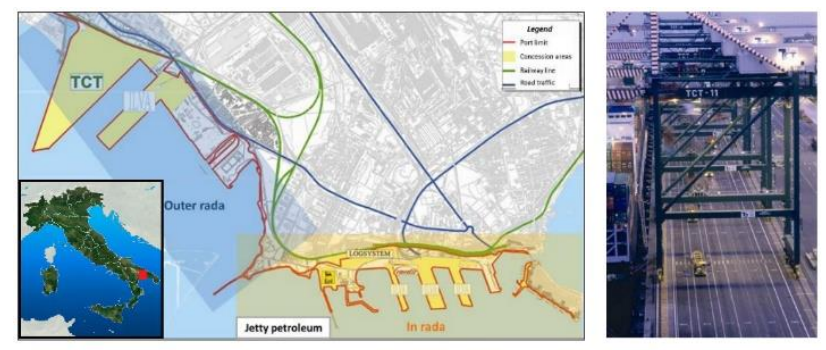

Figure 1. The Port of Taranto: plan of the area (left) and panoramic image of TCT (right)

The operation of the quays is guaranteed throughout the year from natural and synthetic protections of maritime works in addition to 
the low tidal range. The port of Taranto has two access channels: the first in rada of the port service with width and depth capable of providing, in an efficient and safe way, the maneuver of naval units of considerable size; the second service of the port outer rada where operate the container terminal and the export terminal at ILVA.

The port outer rada is located to the west, between the Jetty Petroleum and the left bank of the river Tara (Multipurpose Wharf) and consists of protruding V, Calata 5 and Multipurpose Wharf. In particular, the Multipurpose Wharf and Calata 5 are operated by Taranto Container Terminal S.p.A. company operating the container terminal.

The wharf on which insists the container terminal has a front of $1800 \mathrm{~m}$ and a variable width between $14 \mathrm{~m}$ and $15.5 \mathrm{~m}$; this area is served by a beam of 5 tracks of $1200 \mathrm{~km}$ and directly connected to the national rail network.

The TCT has facilities to load and unload container trains thanks to two rail-mounted gantry crane which provide for the loading/unloading of the containers by the trains in quick time. It also has 10 gantry cranes for operations between ship and shore also on rails.

\subsection{Inspection of runways}

During the useful life of lifting infrastructure must be inspected periodically in order to establish whether they comply with the tolerances established by agreement between the entity controller and users not taking into account any elastic deformations occurring during operation (Bevilacqua et al., 2008).

Between the main steps of the periodic system checks the following investigations are planned (Figure 2):

1. tolerance of span $\mathrm{S}$ of the crana rails related to rail centre at each point of travelling track (Figure 2a)

2. tollerence of horizontal straightness of rail head at each point of travelling track; tolerance of horizontal straightness related to test length of $2000 \mathrm{~mm}$ (sample value) at each point of rail head (Figure 2b);

3. tolerance of straightness related to height of crane rail centre each point travelling track; tolerance of straightness related to test length of $2000 \mathrm{~mm}$ (sample value) at each point of height of crane rail (Figure 2c)

4. usury of the sliding rail head.

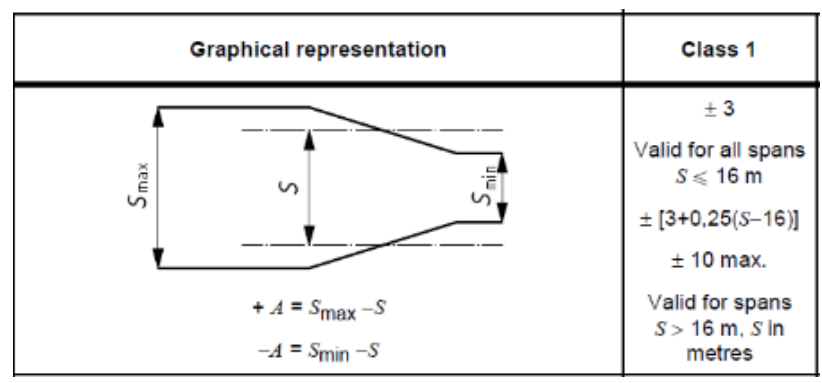

(a)

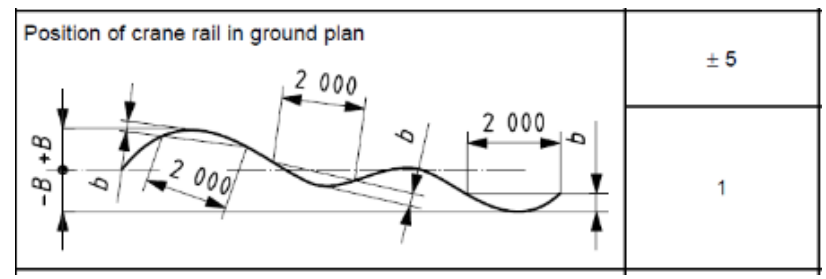

(b)

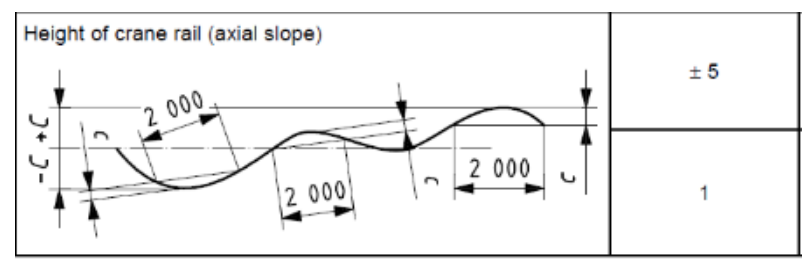

(c)

Figure 2. Construction tolerances for travelling tracks of class 1

Regard to the parallelism of the runways the distance between the rails must not deviate $\pm 3 \mathrm{~mm}$ from the nominal size.

The difference in height between the two rails cannot be higher than $0.15 \%$ of their distance and, in any case, cannot exceed $10 \mathrm{~mm}$.

The lateral movement of the rails, or the deviation between the theoretical and the actual arrangement of the centre line of the rail, considering a section of length equal to $2 \mathrm{~m}$, cannot be more than $\pm 1 \mathrm{~mm}$. In addition, there must be no misalignments junctions of the rails (UNI ISO 8306). The maximum usury and strain on the rail head is equal to $7 \%$ of the nominal size (Sivilotti, 2009).

\section{METHOD AND DATA}

\subsection{Method}

Before to describe a suitable method of analysis, it is necessary to perform an aerial survey in order to identify the possible criticalities of a place by the building of an orthophoto in high geometric resolution.

The monitoring of rail crane was performed trough different technique of survey: topographic, photogrammetric and TLS.

The topographic survey was used to determine the plane height of the rails and the parallelism between the tracks, as well as the measurement of the CGP required for the georeferencing of the photogrammetric and laser scanner surveys.

The TLS survey was carried out in order to construct a threedimensional model and consequently identify the significant sections on which to check for any wear of the tracks.

Finally, through the photogrammetric survey it was possible to extract the profiles in the selected sections to be compared with the theoretical model of the track.

The anomalies found were compared with the tolerances provided by the ISO standards. The workflow of the activities is shown in the following figure (Figure 3)

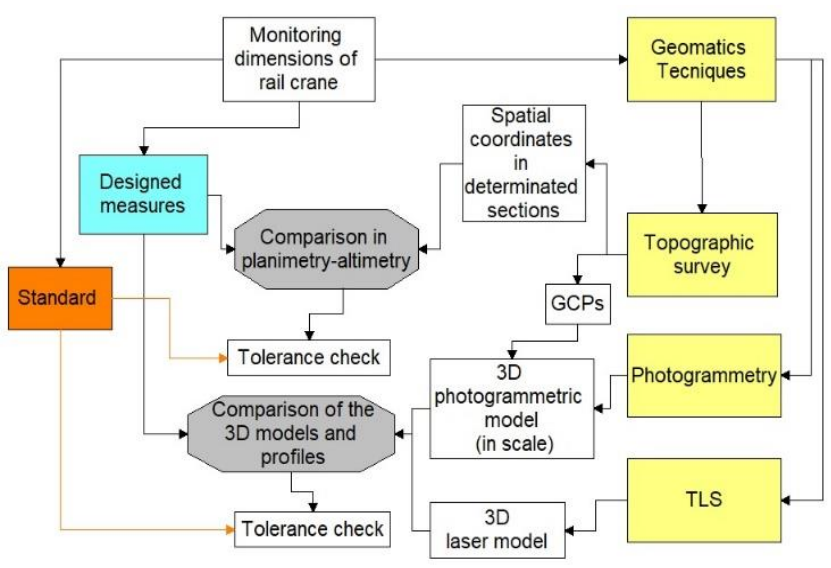

Figure 3. Pipeline of the applied method 


\subsection{Geomatics data}

\subsubsection{Identification of the study area by UAV photogrammetry}

For a detailed characterization of the study area, a photogrammetric survey was prepared using an unmanned aerial vehicle (UAV), commonly known as drone.

The ANAFI drone (produced by Parrot company) was used. This UAV is equipped with an imaging system composed of a 1/ .4" CMOS-LD-ASPH sensor (low dispersion aspherical lenses) with a focal aperture of $\mathrm{f} / 2.4$ and a $35 \mathrm{~mm}$ format equivalent to $23 \mathrm{~mm}$

The survey was planned using the freeware Mission Planner software; once that the survey area was defined through a flyover grid, the reference values of the camera supplied with the drone have been set in the Camera Configuration panel (focal length, image width, height, sensor, etc ...) as well as a series of other parameters such as flight height and speed.

By entering the above values, the simulator automatically recognizes this setting; in this way, it is possible to view the mission in all its characteristics: distance between images, shutter speed between two images, GSD, total images, flight time, etc.

The survey was planned in order to obtain an image resolution (GSD of $5 \mathrm{~cm}$ ). In this way, the images generated to this resolution allow to appreciate the details of the tracks, the crane and, more generally, the port infrastructure.

The flight planning was designed in order to obtain for each pair of images, an overlap of about $80 \%$ in the longitudinal direction (overlap) and a sidelap of $60 \%$ with the adjacent one (Pepe et al., 2018)

The planned survey in this way allowed to obtain a dataset of images that were processed using Agisoft Photoscan stand-alone software.

As known, this commercial software is based on a multi-view 3D reconstruction and is able to orientate a very high number of images: the workflow has therefore provided for the orientation of the images detected, a process in which the calibration parameters of the camera are automatically refined. Subsequently, the point cloud (dense cloud) was processed using dense image matching algorithms, obtaining about 35 million points.

Subsequently, a pattern of polygonal and textured meshes was created. The scaling and geo-referencing of the model was realized through the identification, directly on the images, of GCPs (Ground Control Points) appropriately positioned on the area under investigation. In the post-processing phase, each identified target has been assigned the values of the spatial coordinates obtained by GNSS survey in NRTK mode, or better using the real time correction from the permanent stations (Pepe, 2018).

Finally, an orthophoto in UTM33-ETRF2000 (Universal Transverse Mercator, fuse 33 - European Terrestrial Reference Frame) projection of the survey area was generated.

\subsubsection{Topographic survey}

The instrumentation used for the assessment of tolerances relating to parallelism, to the difference in level and the straightness of the rails has consisted of a motorized total station Leica TCRA 1101 and an optical level Leica NA2 with groundparallel plate (Mazalová, 2009; Sokol, 2008).
According to the manufacturer the total station Leica TCRA 110 has an accuracy of 1.5 arc seconds ( $0.5 \mathrm{mgon})$ for both circles. The vertical is determined by a liquid compensator, just like in the 1961 Wild T1A, although the technical implementation is differs completely.

The accuracy of this vial is 0.5 arc seconds $(0.2$ mgon) with a 4 arc minute (70 mgon) working range.

In normal use the EDM measures a distance in 1 second with an accuracy of 0.002 metres up to a distance of 3.5 kilometres using a single Leica round prism. Using 3 prisms this can be extended to about 5.4 kilometres. In addition to that it can measure distances to reflection tape up to 250 metres, and without prism or reflection tape up to 80 metres.

Using the extra power of the reflectorless mode distances up to and above 9 kilometres can be achieved when combined with 3 Leica prisms.

The NA2 automatic level is the flagship optical level product from Leica Geosystems. Designed by leading surveyors and developed by highly skilled engineers with a great deal of experience in knowing what an instrument must achieve in the field.

Created for all types of surveying task, the NA2 is highly precise and efficient when doing routine levelling task on building sites, for geodetic control at all levels of accuracy, and in engineering projects. For additional precision it can be coupled with the optional GPM3 Parallel Plate Micrometer. The accuracy standard deviation per $\mathrm{km}$ double run is up to $0.7 \mathrm{~mm}$.

The survey techniques adopted have provided for the adoption of polygonal open with relative determination of the ideal axis coordinate of the West denominated rails $(\mathrm{E})$ and West $(\mathrm{W})$ relative to each line of stroke (Figure 4) with a sampling interval equal to $2 \mathrm{~m}$.

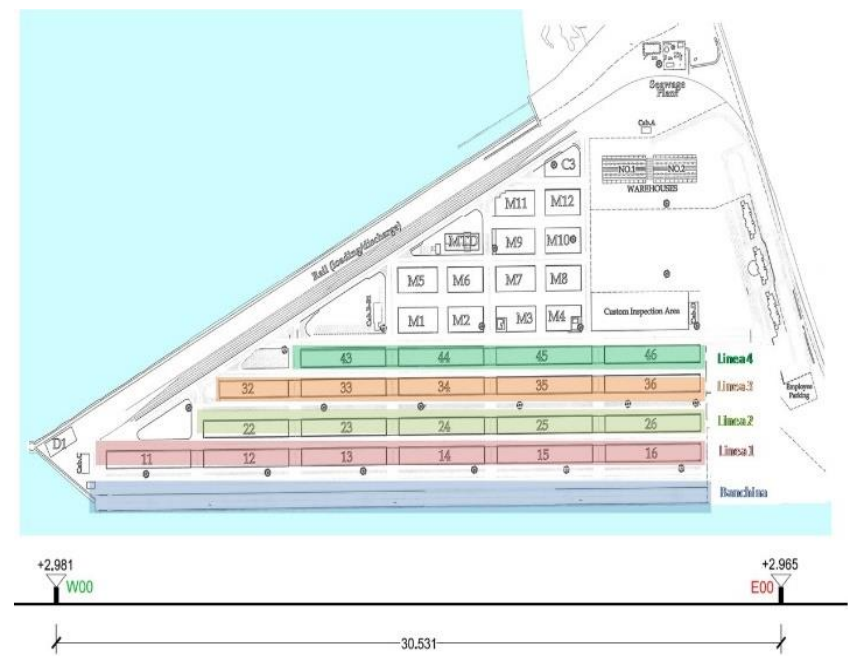

Figure 4. Racing lines and identification of rails

The activities survey have been designed by providing the most suitable and the most reliable technical type of instrumentation. At the end of this step, it was decided to proceed with integrated survey: the direct measurement of the phenomenon, the use of the terrestrial laser scanner and the photogrammetric technique.

In order to check the state of usury of the rails, were identified, materialized and monographed 100 control sections, the average length of $1.00 \mathrm{~m}$, evenly spaced along the quay and the lines (1-4), will depend on the visual presence or absence of wear phenomena also localized (Figure 5) and located using laser scanner survey. 


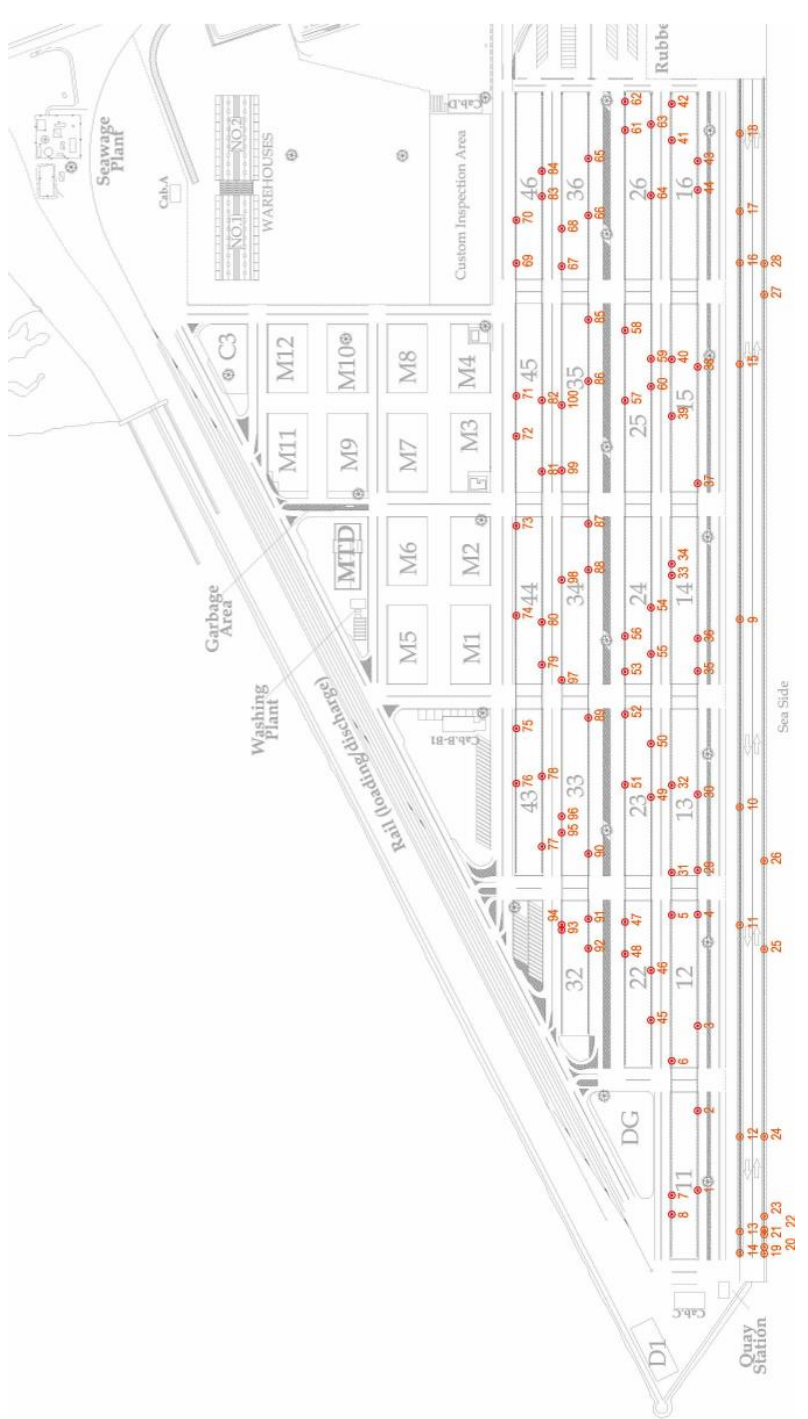

Figure 5. Identification of the sections controlled

The direct survey activity was achieved by providing for the construction of a standard frame in order to detect four of the rail sections (Figure 6a) through the accurate measurement of the profile of the mushroom implemented through comb and that of dimensional wear occurs by means of calibre with vernier reading to $1 / 20$ precision.

The structure under investigation is the crane rail realized according to DIN 536 technical specifications, as shown in the Figure 6b.

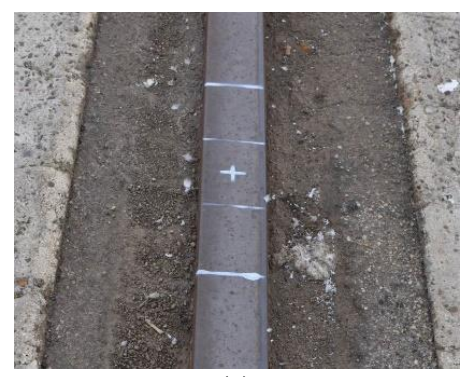

(a)

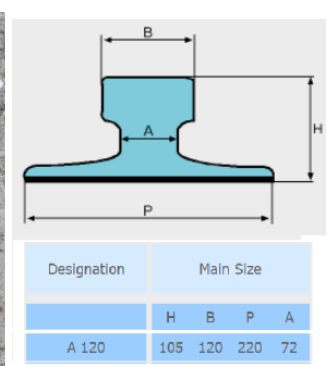

(b)
Figure 6. Crane rail under investigation. a) Panoramic photo of sections highlighted by standards frame for direct survey; b) technical features of crane rail (the measures are expressed in millimetres)

\subsubsection{Terrestrial scanner survey}

The laser scanner survey were carried out with Leica 6200 instrument. For each rail have been acquired two scans later aligned. The point cloud has been elaborated in Geomagic Studio software (Costantino et al., 2013; Costantino et al., 2015).

By means of such software it has been performed the filtering of the data, which has allowed to eliminate the noise associated to the reflectivity of the material, environmental conditions, etc., and the subsequent modeling of the same with the consequent extraction of the sections with arbitrary step. In particular, after reading the entire dataset and intercepting the possible sections which presented higher problems has been carried out the photogrammetric survey (Figure 7).
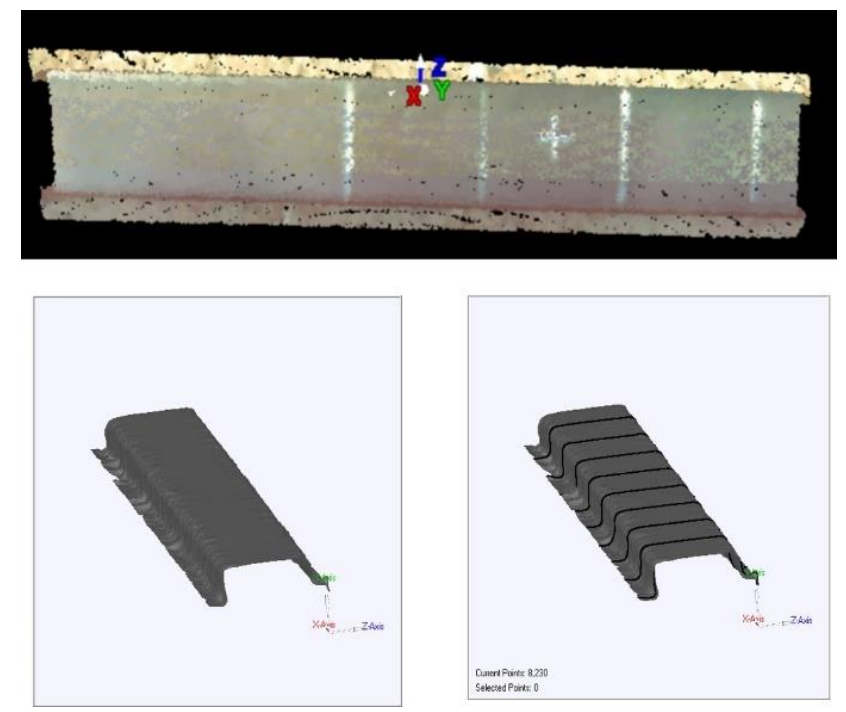

Figure 7. Point Cloud aligned in Cyclone and 3D model with section in Geomagic

\subsubsection{Terrestrial photogrammetric survey}

The terrestrial survey was carried out using a Digital single-lens reflex (DLSR) Nikon D5000, which is a 12.3-megapixel DXformat.

A total amount of 82 images was performed. As known, the modelling of the scene is the result of chaining two computer vision-based pipelines: "Structure-from-Motion" (SfM) and "Multi View Stereo" (MVS).

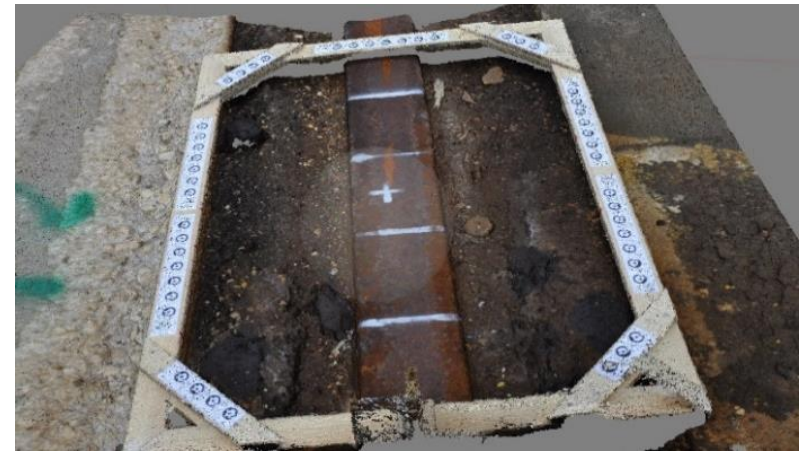

Figure 8. Point cloud performed by Agisoft PhotoScan software 
Generally, most of the software available on the market have a high degree of automation where the different steps of each pipeline are clearly shown and, at same time, allow, step by step, to control the quality of the photogrammetric data (Callieri et al., 2011). In order to investigate the impact in building 3D model by choosing different software (Luhmann et al., 2007) the postprocessing of the images was carried out using two commercial software: Agisoft Photoscan and 3DF Zephir.

According the photogrammetric pipeline, the 3D point cloud of the crane rail was performed. In particular, in Photoscan was generated a dense point cloud of 35 million of points while in 3DF Zephir of 23 million of point. For example, in the Figure 8 is shown the $3 \mathrm{D}$ point cloud generated in Agisoft Photoscan environment.

\section{RESULTS}

\subsection{Comparison between TLS and terrestrial photogrammetry point clouds}

Since that both a laser scanner and a photogrammetric survey were performed, it was possible to perform a comparison between the two point clouds (Barazzetti et al 2010). The comparison between the point clouds were carried out in CloudCompare software. Also, in this case, the difference between the point clouds is really small, as shown in figure 9 .

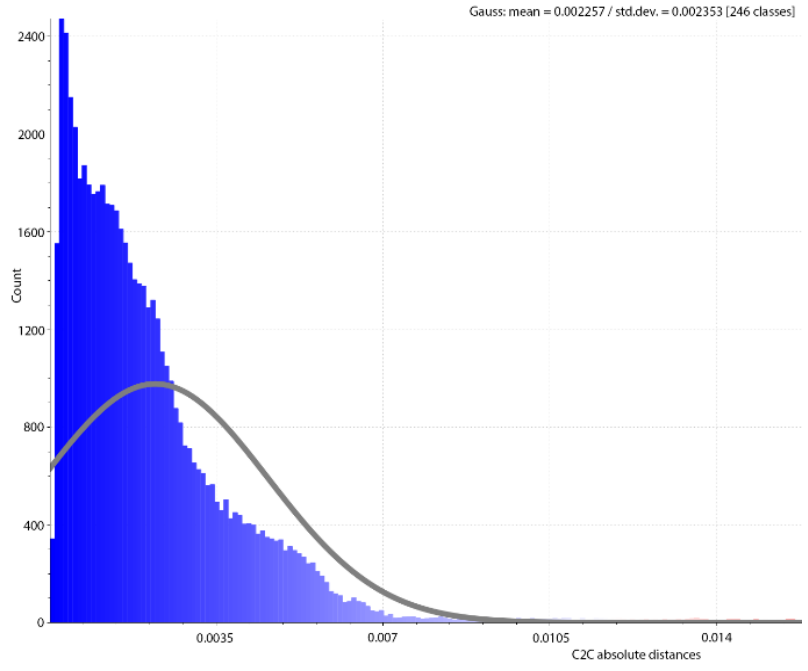

Figure 9. C2C absolute distance between TLS and photogrammetric point clouds with indication of the Gauss distributor

\subsection{Profile analysis}

Therefore, once obtained the 3D point cloud, it was imported into Geomatics software for the production of sections having a higher resolution and accuracy than those coming from the TLS so as to define the state of usury of the rail. Knowing the dimensions and characteristics of the track, it was possible to make a comparison between the latter and the different profiles that can be extracted in the different sections. An example of profiles comparison (Figure 10) allowed to check the usury of the structure.

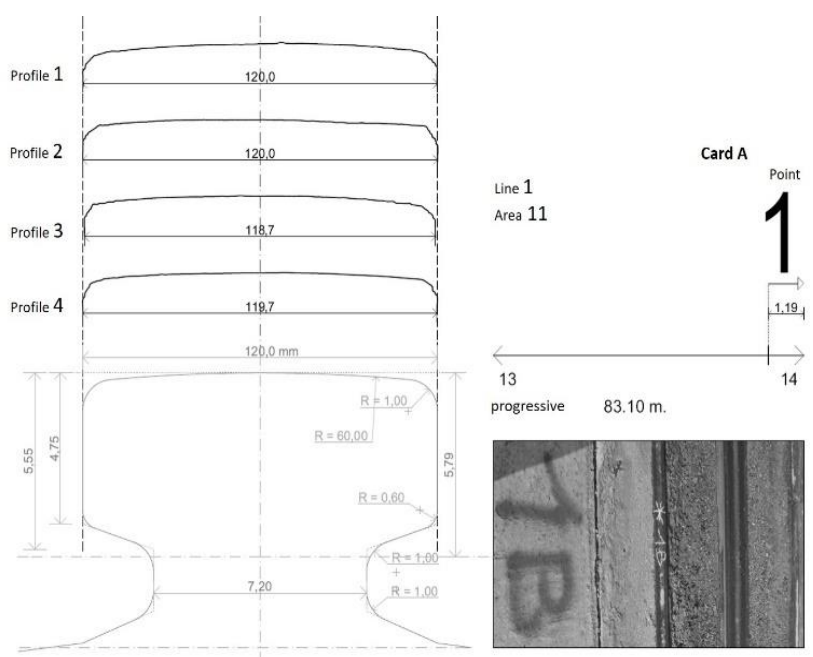

Figure 10. Evaluation of wear through a comparison of profiles

In addition, the same photogrammetric technique allowed the production of orthophotos too, as shown in the Figure 11. In this way, it was possible to analyze by the texture some phenomena, such as the corrosion, cracking and so on.

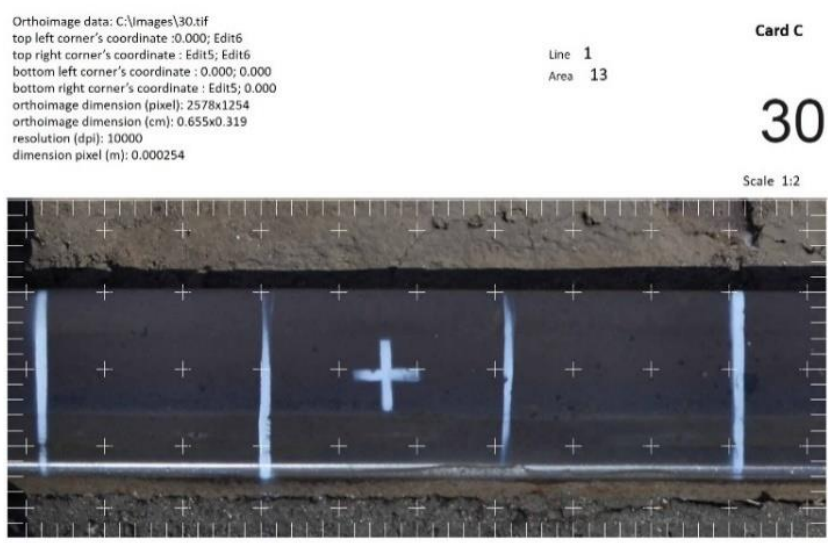

Figure 11. Orthophoto of the investigated sections

Through direct survey has been possible to verify the presence of the wear phenomena (Figure 12), the laser scanner technique through the extract sections has allowed the analysis on the recognition of the timely and widespread phenomenon, while the photogrammetric gave the wear values occurred metrically with the calibre.

The survey techniques adopted have allowed the verification of the rail section. The results obtained were tabulated indicating the presence of any elements out of tolerance, it was however found that the $98 \%$ of the samples detected values were within the prescribed limits, also the most problems of wear were found along the quay attributable to corrosive phenomena being this facing the sea and therefore subject to strong marine agents. 


\begin{tabular}{|c|c|c|c|c|c|c|c|c|c|c|}
\hline \multirow{2}{*}{ Line } & \multicolumn{2}{|c|}{ Sections } & \multirow{2}{*}{$\begin{array}{l}\text { Tolerance } \\
(7 \%)(\mathrm{mm})\end{array}$} & \multicolumn{6}{|c|}{ DIRECT SURVEY } & \multirow{2}{*}{$\begin{array}{c}\text { Check } \\
\text { wear } \\
\text { tolerance }\end{array}$} \\
\hline & 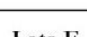 & & & Profile 1 & Profile 2 & Profile 3 & Profile 4 & Mean Sec. & $\begin{array}{l}\text { Ideal section } \\
\text { difference }(\mathrm{mm})\end{array}$ & \\
\hline Banchina & 21 & & 8,4 & 115,3 & 116,8 & 116,5 & 115,4 & 116,0 & 4,0 & ok \\
\hline Banchina & 23 & & 8,4 & 114,8 & 116,4 & 117,8 & 115,9 & 116,2 & 3,8 & ok \\
\hline Banchina & 24 & & 8,4 & 114,5 & 114,8 & 117,2 & 115,2 & 115,4 & 4,6 & ok \\
\hline Banchina & 25 & & 8,4 & 114,4 & 116,1 & 116,9 & 117,3 & 116,2 & 3,8 & ok \\
\hline Banchina & ......... & $\ldots \ldots \ldots$ & $\ldots \ldots \ldots$ & $\ldots \ldots \ldots$ & $\ldots \ldots \ldots$ & $\ldots \ldots \ldots$ & $\ldots \ldots \ldots$ & $\ldots \ldots \ldots$ & $\ldots \ldots \ldots$ & $\ldots \ldots \ldots$ \\
\hline 1 & 35 & & 8,4 & 117,1 & 117,6 & 116,2 & 116,8 & 116,9 & 3,1 & ok \\
\hline 1 & 36 & & 8,4 & 115,0 & 117,1 & 117,4 & 115,5 & 116,3 & 3,8 & ok \\
\hline 1 & & 31 & 8,4 & 117,1 & 119,5 & 110,0 & 120,2 & 116,7 & 3,3 & ok \\
\hline 1 & ......... & ......... & $\ldots$ & ........ & ........ & ....... & $\ldots \ldots$. & ....... & ......... & ........ \\
\hline 2 & 59 & & 8,4 & 115,8 & 118,1 & 120,5 & 117,3 & 117,9 & 2,1 & ok \\
\hline 2 & 60 & & 8,4 & 117,2 & 117,6 & 117,2 & 119,7 & 117,9 & 2,1 & ok \\
\hline 2 & & 47 & 8,4 & 117,4 & 116,3 & 117,0 & 119,1 & 117,5 & 2,5 & ok \\
\hline 2 & ......... & $\ldots \ldots \ldots$ & $\ldots \ldots \ldots$ & $\ldots \ldots \ldots$ & $\ldots \ldots \ldots$ & $\ldots \ldots \ldots$ & $\ldots \ldots \ldots$ & $\ldots \ldots \ldots$ & $\ldots \ldots \ldots$ & $\ldots \ldots \ldots$ \\
\hline 3 & 86 & & 8,4 & 117,8 & 117,8 & 116,6 & 117,9 & 117,5 & 2,5 & ok \\
\hline 3 & 88 & & 8,4 & 115,8 & 118,5 & 116,1 & 116,1 & 116,6 & 3,4 & ok \\
\hline 3 & & 96 & 8,4 & 115,9 & 118,8 & 119,6 & 118,2 & 118,1 & 1,9 & ok \\
\hline 3 & $\ldots \ldots \ldots$ & $\ldots \ldots \ldots$ & $\ldots \ldots \ldots$ & $\ldots \ldots \ldots$ & $\ldots \ldots \ldots$ & $\ldots \ldots \ldots$ & $\ldots \ldots \ldots$ & $\ldots \ldots \ldots$ & $\ldots \ldots \ldots$ & f........ \\
\hline 4 & 77 & & 8,4 & 119,9 & 118,1 & 117,6 & 119,6 & 118,8 & 1,2 & ok \\
\hline 4 & 78 & & 8,4 & 118,1 & 120,0 & 120,0 & 116,9 & 118,8 & 1,3 & ok \\
\hline 4 & $\ldots \ldots \ldots$ & $\ldots \ldots \ldots$ & ......... & …...... & .......... & ......... & ......... & $\ldots \ldots \ldots$ & $\ldots \ldots \ldots$ & $\ldots \ldots \ldots$ \\
\hline
\end{tabular}

Figure 12. Results of the verification binary wear and control with calibre

The reference system employed for data representations has been set for each operating line at the origin of the western rail by imposing the $\mathrm{Y}$ axis, which coincides with the ideal of the rail axis, positive towards the root of the wharf and the $\mathrm{X}$ axis in the orthogonal direction, and share attributed arbitrarily the origin of 3 m (Gašinec, 2009).

In figures 13 and figure 14, we are given the results of the checks carried out, highlighting the anomalies. In addition, in the figures were reported extracts that highlight the non-compliance with the prescribed requirements. For each line were calculated the percentages of a fault relating to the entire extension of the lines:

$\checkmark$ quay approximately equal to $5 \%$ by altimetry, to $32 \%$ in planimetry and to $15 \%$ in straightness;

$\checkmark$ line 1 , about $16 \%$ in altitude, $25 \%$ in floor plan and $10 \%$ in straightness;

$\checkmark \quad$ line 2 , about $17 \%$ in altitude, $10 \%$ in floor plan and $12 \%$ in straightness;

$\checkmark \quad$ line 3, equal to about $8 \%$ by altimetry, $0 \%$ in planimetry and $5 \%$ in straightness;

$\checkmark \quad$ line 4 , about $6 \%$ in altimetry, $0 \%$ and $6 \%$ in plan in straightness.

The biggest and most obvious problems were found at the lines containing the most intense exercise activities.

\begin{tabular}{|c|c|c|c|c|c|c|c|c|}
\hline \multicolumn{9}{|c|}{ QUAY (nominal rails wheelbase $30,5 \mathrm{~m}$ ) } \\
\hline SECTION & Progressive & Quote E & Quote W & $\Delta Q$ & $\begin{array}{c}\text { rails } \\
\text { wheellase }\end{array}$ & $\Delta \mathrm{I}$ & $\begin{array}{c}\text { Check } \\
\text { tolerance } \\
\Delta Q\end{array}$ & $\begin{array}{c}\text { Check } \\
\text { tolerance } \\
\Delta l\end{array}$ \\
\hline 128 & 763,42 & 2,987 & 2,997 & 0,010 & 30,527 & 0,027 & ok & ok \\
\hline 129 & 769,42 & 2,988 & 2,993 & 0,005 & 30,521 & 0,021 & ok & ok \\
\hline 130 & 775,27 & 2,985 & 2,993 & 0,008 & 30,524 & 0,024 & ok & ok \\
\hline 131 & 781,35 & 2,984 & 2,991 & 0,007 & 30,529 & 0,029 & ok & ok \\
\hline 132 & 787,31 & 2,989 & 2,993 & 0,004 & 30,534 & 0,034 & ok & no \\
\hline 133 & 793,15 & 2,985 & 2,991 & 0,006 & 30,533 & 0,033 & ok & no \\
\hline 134 & 799,24 & 2,987 & 2,995 & 0,008 & 30,533 & 0,033 & ok & no \\
\hline \multicolumn{9}{|c|}{ UINE 3 (nominal rails wheelbase $32,2 \mathrm{~m}$ ) } \\
\hline 7 & 37,57 & 2,904 & 2,884 & 0,020 & 32,1850 & 0,0150 & ok & ok \\
\hline 8 & 41,63 & 2,905 & 2,883 & 0,022 & 32,1820 & 0,0180 & ok & ok \\
\hline 9 & 47,77 & 2,912 & 2,882 & 0,030 & 32,1840 & 0,0160 & ok & ok \\
\hline 10 & 54,07 & 2,914 & 2,884 & 0,030 & 32,1860 & 0,0140 & ok & ok \\
\hline 11 & 59,71 & 2,92 & 2,88 & 0,040 & 32,1870 & 0,0130 & no & ok \\
\hline 12 & 65,77 & 2,927 & 2,878 & 0,049 & 32,1830 & 0,0170 & no & ok \\
\hline 13 & 71,68 & 2,934 & 2,875 & 0,059 & 32,1900 & 0,0100 & no & ok \\
\hline 14 & 77,64 & 2,939 & 2,874 & 0,065 & 32,1880 & 0,0120 & no & ok \\
\hline
\end{tabular}

Figure 13. Testing the parallelism and of the level difference of the rails

\begin{tabular}{|c|c|c|c|c|c|c|c|}
\hline Line & Rail & Code & $\mathrm{x}(\mathrm{m})$ & $y(m)$ & \multicolumn{2}{|c|}{$\Delta \mathrm{x}(\mathrm{m})$} & $\begin{array}{c}\text { Check } \\
\text { tolerance } \\
\Delta \mathrm{x}\end{array}$ \\
\hline \multirow{20}{*}{ LINE 1} & \multirow{10}{*}{ Est } & E00 & 30,573 & 2,424 & \multirow{2}{*}{0,004} & & no \\
\hline & & E.01 & 30,577 & 4,526 & & \multirow{2}{*}{0,003} & no \\
\hline & & E02 & 30,580 & 6,628 & \multirow{2}{*}{0,002} & & no \\
\hline & & E03 & 30,582 & 8,561 & & & no \\
\hline & & E04 & 30,582 & 10,493 & & & no \\
\hline & & E05 & 30,579 & 12,426 & $-0,003$ & & no \\
\hline & & $\mathrm{E} 06$ & 30,582 & 14,429 & & 0,003 & no \\
\hline & & F.07 & 30,580 & 16,433 & $-0,002$ & & no \\
\hline & & E08 & 30,583 & 18,436 & & 0,003 & \\
\hline & & & & & $\ldots$ & & \\
\hline & \multirow{10}{*}{ Ovest } & W00 & 0,041 & 1,843 & \multirow{2}{*}{0,003} & & no \\
\hline & & W01 & 0,044 & 4,102 & & \multirow{2}{*}{0,003} & no \\
\hline & & W02 & 0,047 & 6,360 & \multirow{2}{*}{0,004} & & no \\
\hline & & W03 & 0,051 & 8,377 & & \multirow{2}{*}{0,004} & no \\
\hline & & W04 & 0,055 & 10,394 & \multirow{2}{*}{0,003} & & no \\
\hline & & W05 & 0,058 & 12,411 & & \multirow{2}{*}{0,001} & ok \\
\hline & & W06 & 0,059 & 14,386 & \multirow{2}{*}{0,000} & & ok \\
\hline & & W07 & 0,059 & 16,362 & & \multirow{2}{*}{$-0,001$} & ok \\
\hline & & W08 & 0,058 & 18,337 & & & \\
\hline & & & & & & & \\
\hline
\end{tabular}

Figure 14. Testing the straightness in a vertical plane of the rail

The importance of signalling of the measurement sections becomes of fundamental importance as the tolerances involved are very low.

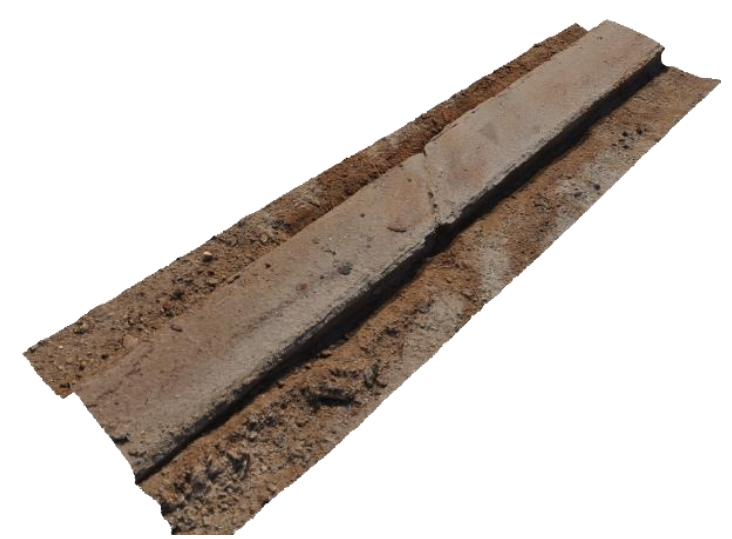

Figure $15.3 \mathrm{D}$ of the structure without indications 
As proof of this, a photogrammetric survey was carried out in the same way as described above, obtaining the three-dimensional model (see figure 15).

In this model, although estimating the possible section plane normal to the rail, it was not possible to be certain that this is accurately determined.

Therefore, it is possible to extract sections of the rail but with some element of uncertainty. However, the result of the overlap shows a difference estimated at around $2 \mathrm{~mm}$ and a slight inclination of the track (figure 16).

The variation could be due to a fracture on the track head as reported in the figure. However, this survey makes it possible to focus more closely on related problems to the discontinuities at the rail joints.

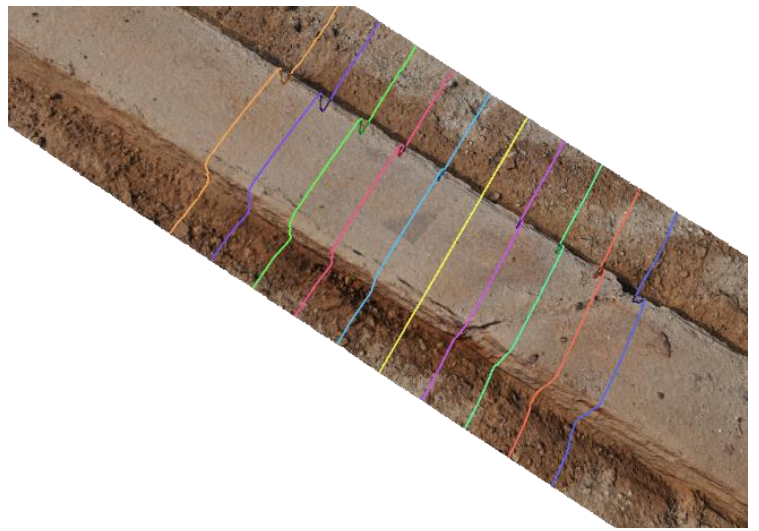

(a)

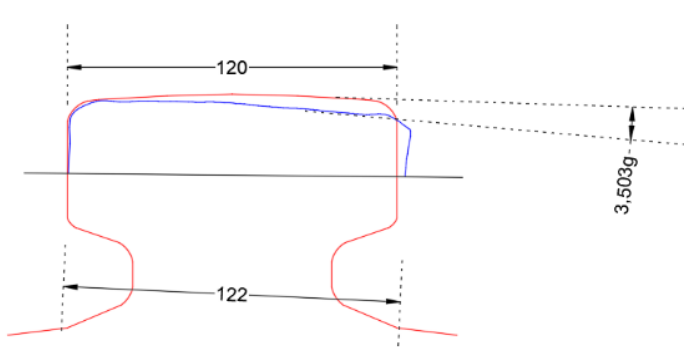

(b)

Figure 16. Profile of the structure. a) indications of the sections; b) comparison between designed profile (red colour) and real model (colour blue)

This variation also contributes to the variation of the track axis, thus distinguishing between the theoretical axis and the practical rail axis.

Once it is known, it is be necessary to report all longitudinal and transversal measures with respect to it.

\section{DISCUSSION}

As shown in paragraph 3.2 , in order to achieve the accuracy required by the regulations, it is necessary to highlight the sections on which to carry out the track wear check before the survey phase.

Rail wear raises the question of the exact location of the track axis; indeed, the tolerances provided for in figure 2 (according to ISO standards) refer to the rail axis. Therefore, if this were to differ significantly from the theoretical one, it would be appropriate to revise the tolerances relating to the altimetric plane of the track and the parallelism between the tracks themselves (Figure 17).

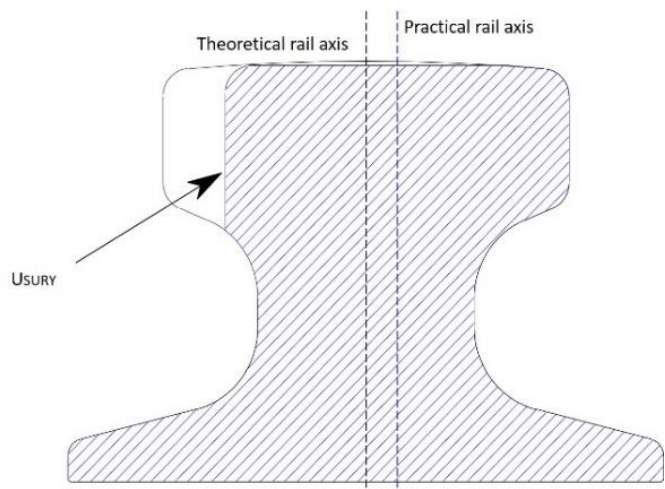

Figure 17. Theoretical and practical rail axis

The 3D model obtained with the photogrammetric technique was found to be more flexible than the one obtained with TLS. In fact, the latter is affected first of all by the environmental conditions around the track and the reflectivity of the surface of the track. In addition, the photogrammetric technique has allowed to detect in greater detail the elements of investigation; for example, any changes in the track due to wear can be evaluated both metrically and through the visual analysis that specifies the phenomenon (such as fracture on the track head).

\section{CONCLUSIONS}

The integration of the several survey techniques allowed to verify the state maintenance rail armament of the lifting systems of the TCT, defining, in an accurate and precise (relative to the order required) the anomalies.

The results of the inspections carried out show that the rails are only locally, deviations of some parameters (straightness, parallelism and height difference) compared to the maximum values allowed by the tolerances, in particular in the sections that, as already mentioned, are located in correspondence with the lines containing the more intense exercise activities and in correspondence of the usual work stations.

Also, the inspection on presence of wear tracks showed localized defects but does not compromise in the short term, the minimum level of security required. Indeed, as reported and describe in the paper, it is necessary to provide for the replacement of some elements of binary whose values are out of tolerance.

Therefore, it is necessary to perform periodic monitoring on the general state of conservation of the rail elements, defined at a rate not exceeding 5 years for major assets and annually for visual examination by technical experts (5.2.1. UNI ISO 9927-1).

\section{ACKNOWLEDGEMENTS}

We want to thank the Port Authority of Taranto for its availability to access the TCT and Donati D'Elia associated projects for the topographic support.

In addition, we want thank DICATECh department for the support in this project. 


\section{REFERENCES}

Barazzetti, L., Scaioni, M., Remondino, F., 2010. Orientation and 3D modeling from marker less terrestrial images: combining accuracy with automation. In The Photogrammetric Record, 25 (132), 356-381.

Bevilacqua, F., Bragatto, P., Nebbioso, A., Pirone, A., Vallerotonda, M. R., 2008. Sicurezza, ambiente e salute negli impianti a rischio di incidente rilevante: verso un sistema integrato dei controlli. Edizione VGR 2006.

Callieri, M., Chica, A., Dellepiane, M., Besora, I., Corsini, M., Moyés, J., Ranzuglia, G., Scopigno, R., Brunet, P., 2011. Mul tiscale acquisition and presentation of very large artifacts: The case of Portalada. In Journal on Computing and Cultural Heritage (JOCCH), 3 (4), 1-14.

Costantino D., Angelini M. G., 2013. Topographic survey for structural monitoring, case: Quadrifoglio condominium (Lecce). The International Archives of the Photogrammetry, Remote Sensing and Spatial Information Sciences, vol. XL-5/W3, "The Role of Geomatics in Hydrogeological Risk" eISSN: 2194-9034, doi:10.5194/isprsarchives-XL-5-W3-179-2013; pp. 179-187, 2728 February 2013, Padua (Itay).

Costantino, D., Angelini, M.G., 2015. Three-Dimensional Integrated Survey for Building Investigations. Journal of Forensic Sciences, 60 (6), 1625-1632.

Dennig, D., Bureick, J., Link, J., Diener, D., Hesse, C., \&Neumann, I., 2017. Comprehensive and highly accurate measurements of crane runways, profiles and fastenings. Sensors, 17(5), 1118.

Luhmann, T., Robson, S., Kyle, S., Harley, I., 2007. Close range photogrammetry. Wiley.

Marjetič, A., Kregar, K., Ambrožic, T., Kogoj, D., 2012. An Alternative Approach to Control Measurements of Crane Rails. Sensors, 12, 5906-5918.

Neumann, I., Dennig, D. Development of the kinematic CraneTrack-Surveying-System "RailControl”. AVN 2012, 5, 162-169.

Pepe, M., Fregonese, L., Scaioni, M., 2018. Planning airborne photogrammetry and remote-sensing missions with modern platforms and sensors. European Journal of Remote Sensing, 51(1), 412-436.

Pepe, M., 2018. CORS architecture and evaluation of positioning by low-cost GNSS receiver. Geodesy and Cartography, 44(2), 36-44.

Remondino F., El-Hakim S., 2006. Image-Based 3d Modelling: A Review. The Photogrammetric Record 21(115), 269-291.

Sivilotti D., Lepore L., 2009. Apparecchi di sollevamento: i controlli e le verifiche secondo le prescrizioni del TU. Prevenzione e protezione Focus TU, www.ambientesicurezza.ilsole24ore.com, 6, 33-45.

\section{Website and regulatory references}

http://www.port.taranto.it/it/documenti-programmatici/47piano-operativo-triennale-2012-2014-dell-autorità-portuale-ditaranto-22-mb.html.

ISO. ISO 12488-1 Cranes-Tolerances for Wheels and Travel and Traversing Tracks-Part 1: General; ISO: Geneva, Switzerland, 2012.

UNI ISO 9927-1 “Apparecchi di sollevamento. Ispezioni. Generalità".

UNI ISO 8306 "Apparecchi di sollevamento. Gru a ponte e a cavalletto. Tolleranza delle vie di corsa". 